\title{
Application of "Clean-up" Cartridge for Gas Chromatographic Determination of Di- and Tri-n-butyltin in Fish
}

\author{
Katsushige Takam,, Hitoshi Yamamoto, Tameo Okumura, Akiyoshi Sugimae \\ and Masao NaKamoto
}

Environmental Pollution Control Center, Osaka Prefectural Government, Nakamichi, Higashinari, Osaka 537

\begin{abstract}
A gas chromatographic method is presented to determine traces of di- and tri-n-butyltin compounds in fish by use of an innovative clean-up cartridge. The cartridge used was packed with a moderately sulfonated low capacity cation exchange resin. The organotin compounds in fish tissue were extracted with hydrochloric acid-ethanol solution as their chlorides, transferred to an ethylacetate/hexane phase by liquid-liquid extraction, and the organic layer was concentrated with a rotary evaporator. The organotin chlorides were trapped on the resin by passing through the cartridge. The sampled cartridge was washed successively with ethanol, water and sodium chloride solution. The trapped organotin compounds were converted to their hydrides by passing a sodium borohydride ethanol solution through the cartridge, and these hydrides were eluted with $1 / 1$ hexane/ ethanol. The eluted organotin hydrides were extracted with hexane by shaking the eluate with water and hexane. The hexane layer was subjected to gas chromatographic separation, and identified by mass spectroscopy. The di- and tri-n-butyltin compounds in a fish sample could be determined as their chlorides with $2.7-4.8 \%$ relative standard deviations in the range $0.1-2.0 \mu \mathrm{g} / \mathrm{g}$. The detection limits of di- and tri- $n$-butyltin compounds as their chlorides were $3 \mathrm{ng} / \mathrm{g}$ and $8 \mathrm{ng} / \mathrm{g}$ for $10 \mathrm{~g}$ of the sample.
\end{abstract}

Keywords Electron capture detection, gas chromatography, butyltin compounds, low capacity cation exchange resin, fish tissue analysis

A great many organotin compounds are used as plastic stabilizers, biocides and fungicides in various fields of industry. These compounds may be discharged or emitted into the environment from industrial products. For instance, tri- $n$-butyltin compounds, added to fishing net materials as stainproof paint to protect the nets in the sea, may be gradually dissolved into the water with use. Shipbottom paints, in which these organotin compounds are utilized to protect the ship from sticky aquatic living materials, may release the species. Recently, organotin compounds were suggested to causing deformation in young yellow tails at fish farms surrounded with fishing nets. On the other hand, organotin compounds have been detected in sediments of harbors. ${ }^{1}$ Therefore, distribution of the compounds in aquatic living creatures and environment must be investigated by developing practical analytical methods, since organotin compounds discharged into rivers and the sea may be concentrated or accumulated in the sediments, aquatic creatures and plants.

So far, a number of analytical methods, such as spectrophotometry ${ }^{2}$, atomic absorption spectrometry ${ }^{3-5,13}$, polarography ${ }^{6}$, gas chromatography $(\mathbf{G C})^{7-10}$ and high performance liquid chromatography ${ }^{11-12}$, have been published. These allow us determine traces of organotin compounds in environmental and biological samples.

Tri- $n$-butyltin compounds are determined by graphite furnace atomic absorption spectrometry in which a clean-up column packed with alumina is used for fish samples. ${ }^{5}$ Tri- and tetra-alkyltin compounds in animal tissues are separately determined by GC with electron capture detection. ${ }^{7}$ Diorganotin compounds in biological tissues are determined by high performance liquid chromatography with fluorescence detection via post column derivatization with Morin Reagent. ${ }^{11}$ Maguire and coworkers ${ }^{8}$ reported that butyltin compounds in environmental samples were successfully determined by a GC-equipped flame photometric detector (FPD) after alkylation with Grignard Reagent. A gas chromatographic-atomic absorption spectrophotometric method (GC-AAS), which utilizes a heated quartz furnace in the light path for AAS, was proposed by Chau et al. ${ }^{13}$ However, these methods were not applied for simultaneous determination of di- and tri- $n$-butyltin compounds in biological samples such as fish tissues.

In this report we describe an innovative clean-up cartridge, packed with a moderately sulfonated cation exchange resin. It is developed to purify effectively the 
di- and tri-n-butyltin compounds in fish samples. The clean-up samples were analyzed by GC or gas chromatography mass spectrometry (GC/MS). The use of the cartridge resulted in accurate and rapid determination of trace levels of the organotin compounds in sea basses and yellow tails from the inland sea and a fishing farm.

\section{Experimental}

\section{Reagents and materials}

Organic solvents used are of pesticide analytical grade from Wako Pure Chemicals Co. (Osaka, Japan). Sodium chloride and hydrochloric acid used are of special grade from Wako. Di- $n$-butyltin dichloride (DBTC) used is of reagent grade from Wako, and trin-butyltin chloride (TBTC) of reagent grade from Tokyo Kasei Kogyo Co. (Tokyo, Japan). The sodium borohydride solution is freshly prepared before use by dissolving $1 \mathrm{~g}$ of sodium borohydride (reagent grade from Wako) in $40 \mathrm{ml}$ of ethanol and removing precipitate. The clean-up cartridge shown in Fig. 1 was prepared in the way reported elsewhere. ${ }^{14}$ The cartridge was conditioned prior to use by washing successively with $20 \mathrm{ml}$ of $1 \mathrm{M}$ hydrochloric acid in ethanol solution, $1 \mathbf{M}$ hydrochloric acid, water, and ethanol.

\section{Apparatus}

A gas chromatograph (Varian Instruments 6000) with an electron capture detector (ECD) was employed. The analytical column was a $2 \mathrm{~m} \times 2 \mathrm{~mm}$ i.d. glass tube packed with $5 \%$ Silicone OV-1 on Gas Chrom Q (100$120 \mathrm{mesh}$ ). The injection temperature was $160^{\circ} \mathrm{C}$, the column temperature was $100-135^{\circ} \mathrm{C}$ (isothermal), and the detector temperature was $250^{\circ} \mathrm{C}$. The carrier gas was nitrogen at a flow rate of $50 \mathrm{ml} / \mathrm{min}$.

A mass spectrometer (JEOL, JMS-DX 300) equipped with a gas chromatograph (Hewlett-Packerd 5790) was employed for identification of di- $n$-butyltin dihydride (DBTH) and tri-n-butyltin hydride (TBTH).

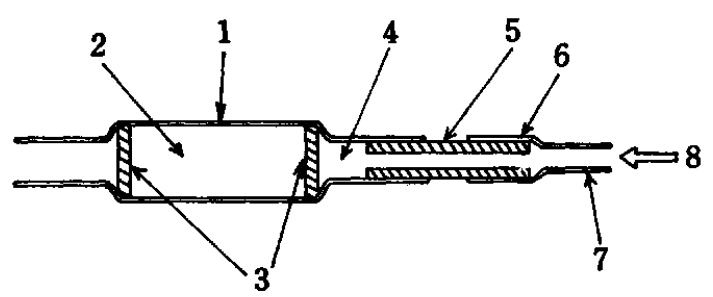

Fig. 1 Clean-up cartridge for DBTC and TBTC from fish sample: (1) Heat shrinkable PTFE tube (7.6 $\mathrm{mm}$ i.d.), (2) cation exchange resin with $0.7 \mathrm{meq} / \mathrm{g}$ of ion exchange capacity synthesized from Mitsubishi Kasei CHP-20P crosslinked polystylene beads and sulfuric acid ${ }^{14}$, (3) glasssintered filter (pore size $30 \mu \mathrm{m}$ ), (4) glass wool, (5) glass tube, (6) heat shrinkable PTFE tube (4.5 mm i.d.), (7) joint for a sample injector, (8) sample flow direction.
The separation column used was a $2 \mathrm{~m} \times 2 \mathrm{~mm}$ i.d. glass tube packed with $5 \%$ Silicone $\mathrm{OV}-1$ on GasChrom $Q$ $(100-120 \mathrm{mesh})$. The column temperature was $90^{\circ} \mathrm{C}$ for DBTH and $145^{\circ} \mathrm{C}$ for TBTH. The carrier gas was helium at a flow rate of $30 \mathrm{ml} / \mathrm{min}$. The operating conditions of the mass spectrometer were as follows. The ionization voltage was $70 \mathrm{eV}$, the ionization chamber temperature was $220^{\circ} \mathrm{C}$ and separator temperature was $250^{\circ} \mathrm{C}$. The measurement of mass fragmentograms was conducted at 120,177 and 179 $\mathrm{m} / \mathrm{z}$ for DBTH and at 177,179 and $235 \mathrm{~m} / \mathrm{z}$ for TBTH.

\section{Calibration for DBTC and TBTC}

DBTC and TBTC were dissolved in ethanol in the range of $0.1-1.0 \mu \mathrm{g} / \mathrm{ml}$. A $2 \mathrm{ml}$ aliquot of each solution was mixed with $2 \mathrm{ml}$ of the sodium borohydride solution and the mixture was mildly shaken for $5 \mathrm{~min}$. Fifteen milliliters of water and $5 \mathrm{ml}$ of hexane were added to the mixture, it was shaken and allowed to stand for $20 \mathrm{~min}$. The hexane layer was used as a standard solution of DBTC and TBTC. A $5 \mu \mathrm{l}$ of the standard was analyzed by GC. Calibration was made by plotting amounts of DBTC and TBTC against corresponding peak heights in the chromatograms.

\section{Analytical procedure}

The flesh part of a fish sample was homogenized. Ten gram amounts of the sample were weighed into a separator funnel, then mixed with $4 \mathrm{ml}$ of $12 \mathrm{M}$ hydrochloric acid and $80 \mathrm{ml}$ of ethanol. The mixture was shaken for $\mathbf{3 0} \mathrm{min}$ and filtered with a Toyo Roshi (Tokyo, Japan) No. 5A filter paper, followed by washing with $20 \mathrm{ml}$ of ethanol. The filtrate was mixed with $200 \mathrm{ml}$ of $10 \%$ sodium chloride solution and $10 \mathrm{ml}$ of $12 \mathrm{M}$ hydrochloric acid and then extracted twice with $80 \mathrm{ml}$ of ethyl acetate/hexane $(3: 2, \mathrm{v} / \mathrm{v})$. The extract was washed three times with $50 \mathrm{ml}$ of water (pH of the washing water became ca. 6). The organic layer was concentrated to $c a .1 .5 \mathrm{ml}$ with a rotary evaporator at $40^{\circ} \mathrm{C}$ and then brought to $10 \mathrm{ml}$ with ethanol.

A 5-10 ml volume of the sample (containing below $5 \mu \mathrm{g}$ of butyltin compounds) was passed through a conditioned cartridge at $1 \mathrm{ml} / \mathrm{min}$. The cartridge was cleaned up by passing $20 \mathrm{ml}$ of ethanol and $10 \mathrm{ml}$ of water at $1-2 \mathrm{ml} / \mathrm{min}$. The cartridge was then treated with $10 \mathrm{ml}$ of $10 \%$ sodium chloride solution, washed with $10 \mathrm{ml}$ of water and then purged with air to exclude water. A $2 \mathrm{ml}$ of the sodium borohydride ethanol solution was forced to pass for 3-5 s through the cartridge by using a syringe, and the eluate (A) was collected. A $5 \mathrm{ml}$ volume of hexane/ethanol $(1: 1, \mathrm{v} / \mathrm{v})$ was passed for 5-10 s and the eluate (B) was collected. The eluates (A) and (B) were combined and shaken with $15 \mathrm{ml}$ of water and $2.5 \mathrm{ml}$ of hexane for 5 min. The mixture was allowed to stand for $30 \mathrm{~min}$. Hydrogen gas generated from the mixture during the extraction was released several times from the container. The cartridges were repeatedly used by condi- 
tioning them prior to the addition of another sample.

A $5 \mu \mathrm{l}$ sample of the hexane layer was analyzed by GC or GC/MS. The identification of DBTH and TBTH was performed by retention time in the chromatogram or GC/MS spectrum and the determination was performed on the basis of the peak height. DBTH and TBTH at lower than $0.02 \mu \mathrm{g} / \mathrm{g}$ were identified with the peak height ratio of $120 \mathrm{~m} / z$ to 177 , and $179 \mathrm{~m} / \mathrm{z}$ and that of $177 \mathrm{~m} / \mathrm{z}$ to 179 , and $235 \mathrm{~m} / \mathrm{z}$ in the GC/MS fragmentgrams, respectively.

\section{Results and Discussion}

Di- and tri- $n$-butylthin compounds $\left(\mathrm{R}_{m} \mathrm{SnX}_{4-m}\right)$ in fish tissue were converted to their chlorides $\left(R_{m}\right.$ $\mathrm{SnCl}_{4-m}$ ) with hydrochloric acid. ${ }^{5,9}$ Ethanol, added to fish tissue to dissolve the fat part, was suitable to collect the organotin chlorides in the sample. Methanol and acetonitrile easily dissolve organotin chlorides but were unsuitable to collect them from fish tissue because the fats might be less than soluble. With $10 \mathrm{~g}$ of a fish sample (sea bass) spiked with 20 $\mu \mathrm{g}$ of DBTC and TBTC, the $100 \%$ recoveries were obtained by use of ethanol, while those by methanol and acetonitrile were $80-90 \%$ and $50 \%$, respectively.

The organotin chlorides in the sample were preliminarily purified by filtering the mixture to exclude solid materials, then transferring the compounds to ethyl acetate/hexane and washing the organic layer with water prior to the clean-up with the cartridge packed with ion exchange resin.

Several sulfonic acid-type cation exchange resins with different ion-exchange capacities were examined to determine the suitability for clean-up of organotin chlorides. The cartridges (shown in Fig. 1) were

Table 1 Effects of ion exchange capacity on recovery of DBTC and TBTC in the clean-up procedure

\begin{tabular}{lcccr}
\hline Resinb & Particle size & $\begin{array}{l}\text { Capacity } \\
\text { (meq/g) }\end{array}$ & \multicolumn{2}{c}{ Recovery, \% } \\
\cline { 3 - 5 } & & DBTC & TBTC \\
\hline No. 1c & $150-300 \mu \mathrm{m}$ & - & 97.4 & 51.6 \\
No. 2d & $150-300 \mu \mathrm{m}$ & 0.07 & 100.9 & 98.4 \\
No. 3d & $150-300 \mu \mathrm{m}$ & 0.7 & 101.0 & 101.5 \\
No. 4d & $150-300 \mu \mathrm{m}$ & 1.3 & 93.9 & 83.9 \\
No. 5d & $150-300 \mu \mathrm{m}$ & 2.0 & 85.2 & 77.4 \\
No. 6e & $100-200 \mathrm{mesh}$ & 5.0 & 39.1 & 13.7 \\
\hline
\end{tabular}

a. A $10 \mathrm{ml}$ volume of ethanol solution containing $10 \mu \mathrm{g}$ of DBTC and $20 \mu \mathrm{g}$ of TBTC was used.

b. A cartridge was packed with $0.6 \mathrm{~g}$ of a cation exchange resin.

c. Mitsubishi Kasei(Tokyo, Japan) CHP-20P cross-linked polystylene beads.

d. Cation exchange resins synthesized from CHP-20P and sulfuric acid under controlled reaction temperature and reaction time.

e. Bio-Rad(Richmond, CA) AG 50W-X8 resin with high ion-exchange capacity. packed with ca. $0.6 \mathrm{~g}$ of the resins. The high capacity cation-exchange resins trapped the compounds well but did not release them after reduction. Table 1 shows that the resins with 0.07 and $0.7 \mathrm{meq} / \mathrm{g}$ of ionexchange capacity gave excellent recoveries for the sample of $10 \mu \mathrm{g}$ of DBTC and $20 \mu \mathrm{g}$ of TBTC in $10 \mathrm{ml}$ of ethanol. In analysis of a fat-rich sample, a cartridge charged with the sample should be washed with more than $50 \mathrm{ml}$ of ethanol to remove the fats. In such a case, the organotin compounds were eluted to some extent with ethanol from the cartridge packed with the $0.07 \mathrm{meq} / \mathrm{g}$ resin. Accordingly, the resin with 0.7 meq/g of ion-exchange capacity was used to prepare the clean-up cartridge. The organotin chlorides could be trapped on the ion exchange resin depending upon ionic interactions with the sulfonyl group on the surface. Since the.compounds tend to elute with free acid in ethanol, the organic extracts should be washed with water until the $\mathrm{pH}$ value of the washing water becomes ca. 6, prior to the clean-up of the cartridge. The cartridge charged with the sample was washed by passing $20 \mathrm{ml}$ of ethanol to exclude organic compounds such as fats. If fat-rich fish tissue is sampled, more than $50 \mathrm{ml}$ of ethanol may be required to remove the fats completely from the cartridge.

After the clean-up, the sulfonic acid-form resin was charged with sodium ion by use of $10 \%$ sodium chloride solution. The residual sodium chlorides and hydrochloric acid formed by ion exchange should be washed out with water, since these species accelerated generation of hydrogen gas from the sodium borohydride in the reduction process. The organotin compounds were instantaneously converted to their hydrides with sodium borohydride in ethanol on the sodium-form resin. The organotin hydrides formed on the resin were readily eluted with ethanol or ethanol/hexane $(1: 1, v / v)$. For $20 \mu \mathrm{g}$ of DBTC and TBTC in $10 \mathrm{ml}$ of ethanol, the recovery of $99-101 \%$ were obtained by using the clean-up procedure. On the other hand, hydrogen gas was vigorously generated on the hydrogen-form resin in the reduction and elution process, and the organotin hydrides were not sufficiently recovered. The organotin hydrides in the combined eluates were quantitatively extracted with hexane by mixing the eluates with more than $10 \mathrm{ml}$ volume of water, and determined by GC or GC/MS. As a substantial amount of hydrogen gas was generated by decomposition of sodium borohydride during the extraction process, it should be released several times to prevent the container from bursting. The extracted organotin hydrides, which were easily oxidized, were stable as long as sodium borohydride was present in the aqueous layer. The hydrides were usually stable in the hexane layer for more than a month at a cool and dark place.

Figure 2 shows a typical gas chromatogram of DBTH and TBTH. An unknown peak in the Fig. 2 may be caused by the contamination of phthalic ester in sodium borohydride. GC analysis was completely 


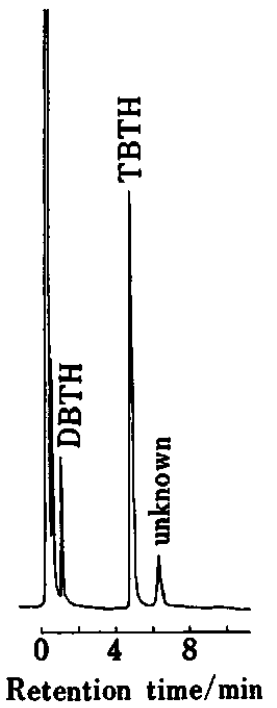

Fig. 2 Typical gas chromatogram of DBTH and TBTH: Column temperature $135^{\circ} \mathrm{C}$; (DBTH) $0.2 \mathrm{ng}$ as DBTC, (TBTH) 2 ng as TBTC.

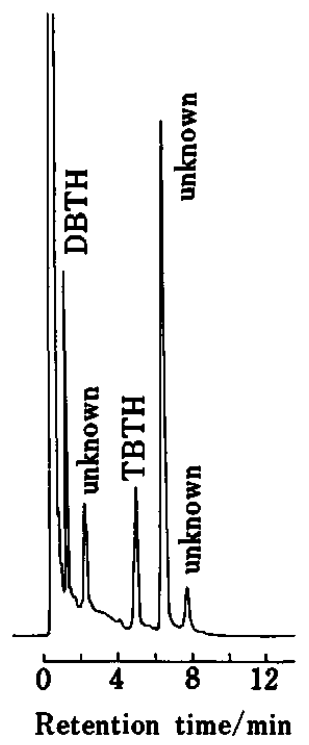

Fig. 3 Typical gas chromatogram of DBTH and TBTH from a fish sample (sea bass): Column temperature $135^{\circ} \mathrm{C}$; (DBTH) $0.023 \mu \mathrm{g} / \mathrm{g}$ as DBTC, (TBTH) $0.054 \mu \mathrm{g} / \mathrm{g}$ as TBTC.

Table 2 Recovery of DBTC and TBTC spiked into fish tissues $^{\mathrm{a}}$

\begin{tabular}{lccccc}
\hline & $\begin{array}{c}\text { Spiked/ } \\
\mu g\end{array}$ & $\begin{array}{c}\text { Found } \\
\mu g\end{array}$ & $\begin{array}{c}\text { SDc/ } \\
\mu g\end{array}$ & $\begin{array}{c}\text { Recoveryb, } \\
\%\end{array}$ & $\begin{array}{c}\text { RSDd, } \\
\%\end{array}$ \\
\hline DBTC & 1.0 & 0.969 & 0.026 & 96.9 & 2.7 \\
& 10.0 & 9.66 & 0.36 & 96.6 & 3.7 \\
TBTC & 2.0 & 1.84 & 0.048 & 91.9 & 2.7 \\
& 20.0 & 18.4 & 0.88 & 91.8 & 4.8 \\
\hline
\end{tabular}

a. $10 \mathrm{~g}$ amount of fish tissues used.

b. Average for five runs.

c. Standard deviation.

d. Relative standard deviation. carried out at $100-135^{\circ} \mathrm{C}$ of column temperature (isothermal) with an excellent resolution and a reasonable analysis time. DBTH and TBTH were linearly determined in the range of $0.04-1.0 \mu \mathrm{g} / \mathrm{ml}$ with $1.3-2.3 \%$ relative standard deviation, and the detection limits of these compound were $0.03 \mathrm{ng}$ for DBTH and $0.08 \mathrm{ng}$ for TBTH.

A recovery test was conducted by using $10 \mathrm{~g}$ of a fish tissue (sea bass) spiked with 1.0-20 $\mu \mathrm{g}$ of DBTC and TBTC. As shown in Table 2, di- and tri-n-butyltin compounds were determined with $2.7-4.8 \%$ relative standard deviation in the range of $0.1-2.0 \mu \mathrm{g} / \mathrm{g}$ as chlorides. The detection limits of di- and tri- $n$-butyltin compounds were $3 \mathrm{ng} / \mathrm{g}$ and $8 \mathrm{ng} / \mathrm{g}$ as chlorides for 10 g of sample.

A number of fish samples were analyzed by the proposed method. Figure 3 shows a typical gas chromatogram obtained from a fish sample (sea bass), and Fig. 4 indicates GC/MS spectra of the DBTH and TBTH identified with GC. In the case of DBTH and TBTH containing lower than $0.02 \mu \mathrm{g} / \mathrm{g}, \mathrm{GC} / \mathrm{MS}$ fragmentation was used to identify them, since it was difficult to identify at such trace levels of hydride with GC/MS spectra. Figure 5 shows that traces of DBTH and TBTH in fish tissue were successfully identified with GC/MS fragmentation. Table 3 reports analytical data for DBTC and TBTC in various fish samples collected at the inland sea, a fish farm and a river. These results suggest that the organotin compounds are potentially accumulated by fishes in the sea.

As these features indicate, the proposed method may be useful for routine analysis of a large number of fish
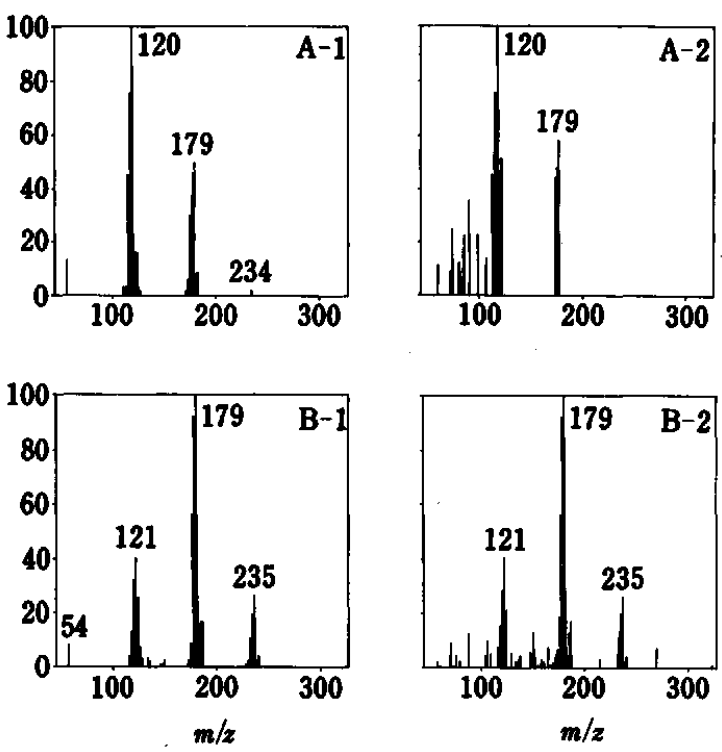

Fig. 4 Identification of the di- and tri-n-butyltin compounds in the fish sample: See Fig. 3 for the fish sample; (A1) standard MS spectrum of DBTH, (A-2) MS spectrum corresponding DBTH, (B-1) standard MS spectrum of TBTH, (B-2) MS spectrum corresponding TBTH. 

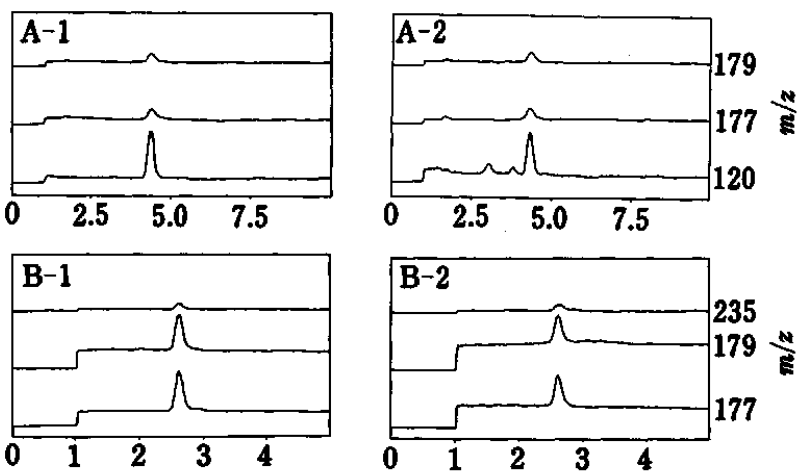

Retention time/min

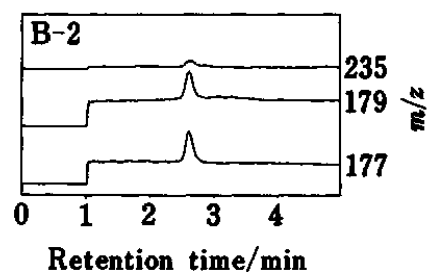

Fig. 5 Typical GC/MS fragmentgrams for DBTH and TBTH in a fish sample (yellow tail): (A-1) standard GC/ MS fragmentgrams of DBTH (0.1 ng as DBTC); (A-2) DBTH $0.01 \mu \mathrm{g} / \mathrm{g}$ as DBTC; (B-1) standard $\mathrm{GC} / \mathrm{MS}$ fragmentgrams of TBTH (0.1 ng as TBTC); (B-2) TBTH, $0.013 \mu \mathrm{g} / \mathrm{g}$ as TBTC.

samples to investigate the distribution and behavior of di- and tri- $n$-butyltin compounds in fishes.

The authors thank Dr. K. Kuwata, Environmental Pollution Control Center, Osaka Prefectural Government, for his helpful advice in preparing the paper. This work was supported in part by Office of Health Studies, Environmental Health Department, Environment Agency.

\section{References}

1. R. J. Maguire, Environ. Sci. Technol., 18, 291 (1984).

2. R. T. Aldridge and B. W. Street, Analyst [London], 106, 60 (1981).

3. R. S. Braman and M. A. Topkin, Anal. Chem., 51, 12 (1979).

4. V. F. Hodge, S. L. Seidel and E. D. Goldberg, Anal. Chem., 51, 1256 (1979).

5. M. Mishima, T. Maruyama, M. Koshiyama, C. Murakami, M. Kumagaya, M. Sumiyoshi, T. Asai, T.
Table 3 Contents of di- and tri-n-butyltin compounds in fish samples

\begin{tabular}{llll}
\hline \multirow{2}{*}{ No. } & \multirow{2}{*}{ Sample } & \multicolumn{2}{c}{ Found $/ \mu \mathrm{g} \mathbf{g}^{-1}$} \\
\cline { 4 - 4 } & & DBTC & TBTC \\
\hline 1 & sea bassa(inland sea) & 0.023 & 0.054 \\
2 & sea bass(inland sea) & 0.025 & 0.19 \\
3 & gray mulletb(inland sea) & N.D.e & N.D.e \\
4 & gray mullet(inland sea) & 0.003 & 0.009 \\
5 & yellow tailc(fish farm) & 0.010 & 0.013 \\
6 & cruciand (river) & N.D. & N.D. \\
\hline
\end{tabular}

a. Sea bass, Leteolabrax japonicus, Cuvier.

b. Gray mullet, Mugil cephalus, Linnaeus.

c. Yellow tail, Seriola quingueradiata, Temminck et Schlegel.

d. Crucian, Carassius auratus, Linnaeus.

e. Not detectable.

Nozawa, Y. Tanaka, N. Matsuzuki, T. Nanpo, K. Ono, M. Takahashi and K. Ito, Bunseki Kagaku, 33, T57 (1984).

6. H. Kitamura, Y. Yamada and M. Nakamoto, Chem. Lett., 1984, 837.

7. Y. Arakawa, O. Wada, T. H. Yu and H. Iwai, J. Chromatogr., 216, 209 (1981).

8. R. J. Maguire and H. J. Huneault, J. Chromatogr., 209, 458 (1981).

9. Y. Hattori, A. Kobayashi, S. Takemoto, K: Takami, Y. Kuge, A. Sugimae and M. Nakamoto, J. Chromatogr., 315, 341 (1984).

10. H. A. Meinema, T. B. Wiersma, G. V. Hann and E. C. Gevers, Environ. Sci. Technol., 12, 288 (1978).

11. T. H. Yu and Y. Arakawa, J. Chromatogr., 258, 189 (1983).

12. K. L. Jewett and F. E. Brickman, J. Chromatogr. Sci, 19, 584 (1981).

13. Y. K. Chau, P. T. S. Wong and G. A. Bengert, Anal. Chem., 54, 246 (1982).

14. K. Takami, K. Kuwata, A. Sugimae and M. Nakamoto, Anal. Chem., 57, 243 (1985).

(Received September 4, 1986)

(Accepted November 17, 1986) 